\title{
Norois
}

Environnement, aménagement, société

La Loire. Sociétés, risques, paysages, environnement

\section{Bouchardy (Christian) (dir.), La Loire. Vallées et vals du grand fleuve sauvage}

Paris, Delachaux et Niestlé, 2002, 288 p. (36€)

Denis Mercier

\section{(2) OpenEdition}

\section{Journals}

Édition électronique

URL : http://journals.openedition.org/norois/967

DOI : $10.4000 /$ norois. 967

ISBN : 978-2-7535-1540-6

ISSN : 1760-8546

Éditeur

Presses universitaires de Rennes

\section{Édition imprimée}

Date de publication : 1 septembre 2004

Pagination : $143-144$

ISBN : 978-2-7535-0054-9

ISSN : 0029-182X

Référence électronique

Denis Mercier, «Bouchardy (Christian) (dir.), La Loire. Vallées et vals du grand fleuve sauvage », Norois [En ligne], 192 | 2004/3, mis en ligne le 26 août 2008, consulté le 23 septembre 2020. URL : http:// journals.openedition.org/norois/967 ; DOI : https://doi.org/10.4000/norois.967

Ce document a été généré automatiquement le 23 septembre 2020

() Tous droits réservés 


\section{Bouchardy (Christian) (dir.), La Loire. Vallées et vals du grand fleuve sauvage}

Paris, Delachaux et Niestlé, 2002, 288 p. (36€)

\section{Denis Mercier}

\section{RÉFÉRENCE}

Bouchardy (Christian) (dir.), 2002. - La Loire. Vallées et vals du grand fleuve sauvage, Paris, Delachaux et Niestlé, 288 p. (36€) 
Les éditions Delachaux et Niestlé nous livrent, dans leur collection « La Bibliothèque du naturaliste », de magnifiques ouvrages d'un point de vue esthétique et scientifique. Le guide sur la Loire, coordonné par Christian Bouchardy, ne fait pas exception dans cette abondante série sur les grandes régions françaises. Les lecteurs de Norois s'intéresseront en priorité à l'ouvrage sur La Normandie, publié en 2001 sous la direction d'Arnaud Guérin, et plus récemment, celui sur La Bretagne, sortie en 2003, piloté par François de Beaulieu, avec notamment la contribution de notre collègue brestois Bernard Hallégouët sur la géographie physique de la Bretagne.

2 L'ouvrage sur la Loire s'organise en huit chapitres.
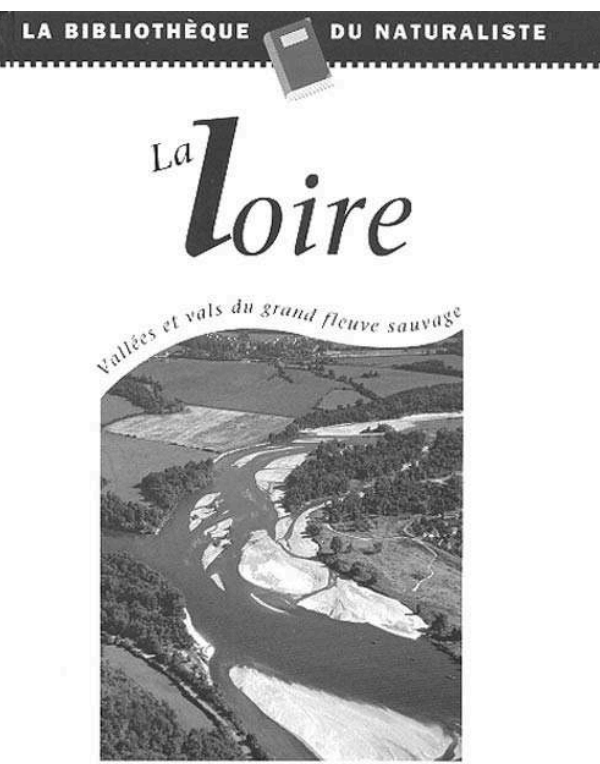

Sous la direction de Christian Bonchardy

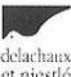

3 Le premier, rédigé par l'éminent géographe clermontois André Fel, propose une esquisse géographique du bassin de la Loire. La présentation ne cherche pas une unité dans ce vaste bassin, mais tente d'aborder des thèmes majeurs (le fleuve, ses crues, ses levées, la navigation, les canaux, l'aménagement, le découpage régional...).

4 Le deuxième chapitre se veut une présentation des «paysages géologiques au fil de l'eau ». Gilbert Cochet brosse le cadre général et l'histoire géologique du bassin de la Loire, d'une manière classique. En revanche, l'approche régionale est passionnante et illustrée de nombreuses photographies, accompagnées parfois de croquis d'interprétation particulièrement pédagogiques.

5 Il faut saluer la présence du troisième chapitre intitulé « hydrologie et géomorphologie fluviale ", rédigé par Jean-René Malavoi. Le concept d'hydrosystème fluvial est au cœur $\mathrm{du}$ discours, avec ses variables de contrôle (flux liquides et solides, pente...), ses variables de réponse, ou d'ajustement (morphologie du lit, largeur, profondeur, sinuosité...). Les concepts clés d'équilibre dynamique, de seuils, d'échelles temporelles et spatiales sont particulièrement bien expliqués. L'approche géomorphologique systémique est ainsi au service d'une bonne gestion des hydrosystèmes. La communauté géographique française dans sa totalité lira avec attention ce chapitre passionnant. À l'heure où la géomorphologie s'affiche telle quelle dans des ouvrages grand public, certains géographes universitaires français voudraient encore scier des branches dynamiques de leur discipline...

6 Le chapitre suivant intitulé « Flore et phytoécologie » a été rédigé par Maryse Tort et Bernard Belin. Il illustre la mosaïque de milieux et d'habitats le long de ce corridor fluvial longitudinal mais aussi dans l'axe transversal. Il montre le poids considérable des dynamiques naturelles et des interventions anthropiques.

7 Le cinquième chapitre sur les vertébrés a été rédigé par quatre collègues naturalistes et propose une analyse des relations entre les oiseaux, reptiles, batraciens, mammifères et 
les milieux dans lesquels ils vivent (pentes boisées, falaises, galets au bord de l'eau, îles et bancs de sable, ripisylves...).

8 Logiquement, le chapitre suivant est consacré aux "milieux aquatiques et poissons " sous la plume d'Yves Souchon. Le patrimoine ichtyologique de la Loire est présenté selon la dimension longitudinale structurante, sans oublier les dimensions verticales et latérales. Ensuite les mesures de protection et de restauration des milieux sont débattues.

9 Le chapitre sur « les invertébrés ligériens » est signé par Jean Faïn et Gilbert Cochet et montre la diversité des milieux entre terre et eau.

10 Le dernier chapitre consacre des pages captivantes aux temps préhistoriques. Frédéric Sumerly nous rappelle que la préhistoire représente $99,99 \%$ de l'histoire de l'Humanité et que le bassin de la Loire, du fait de ses terroirs variés et accueillants, de ses importants gîtes à silex, a très tôt attiré les hommes.

11 Cet ouvrage passionnant montre bien que l'avenir de la Loire passe par une gestion intégrée de toutes ses dimensions. Nous lui souhaitons un large succès auprès du grand public, qui voit par cet ouvrage tout l'intérêt des sciences et notamment de la géographie.

INDEX

Index géographique : France, Loire (fleuve et vallées)

\section{AUTEURS}

DENIS MERCIER 